\title{
Conceptual Study on Hydrogen-Based Integration of Propulsion and Power in Space Transportation System
}

\author{
By Yusuke MARU ${ }^{1)}$, Yoshiaki NAKAUE ${ }^{2}$, Yoshifumi INATANI ${ }^{1)}$ and Hatsuo MORI ${ }^{3)}$ \\ ${ }^{1)}$ The Institute of Space and Astronautical Science, JAXA, Sagamihara, Japan \\ ${ }^{2)}$ Department of Aeronautics and Astronautics, The University of Tokyo, Tokyo, Japan \\ ${ }^{3)}$ IHI Corporation, Tokyo, Japan
}

(Received August 5th, 2015)

\begin{abstract}
A system that integrates on hydrogen-base all of energy on propulsion and power needed in a space transportation system is one of mechanisms for operating reusable space transportation system frequently. In this paper, the concept design for the integrated system is presented to discuss the effectiveness of the system. As evaluation functions, (1) weight, (2) cost, and (3) turn-around time (operability) are considered. Modeling of the energy system is conducted focusing energy flow and connections between elements that configure the energy system. Assuming a space transportation mission and regarding the required energy function in the mission as boundary conditions, conceptual designs of the integrated energy system using the developed model are performed. There is a trade-off relationship between the three evaluation functions. For weight reduction, integration of fuel species and the scale of the energy storing elements, those are an accumulator and a battery, is effective. For reduction of the turn-around time, toxic fuels have to be removed. An adoption of batteries reduces the number of connections between the elements so that it contributes to improvement in operability. As for cost, the part related to the manufacturing depends on weight and that related to the operation does on the turn-around time in the present cost model. Hydrogen and oxygen-based integrated energy system, although additional elements are to be necessary and a disadvantage in terms of weight is caused, is effective in reducing the operating costs and the turn-around time in case that a large amount of high frequency transport is desired because it is possible to improve the operability significantly.
\end{abstract}

Key Words: Propulsion and Power, Integration System, Hydrogen

\section{Introduction}

In order to make space utilization more public, transportation cost to the orbit need to be decreased. So as to reduce the space transportation cost, it is necessary that present expendable transportation system be replaced with reusable one. However, it is not enough that the system can be just reusable. The space transportation system has to be operated frequently like airplane. Though the US STS is reusable system, it cannot be operated frequently, which resulted in that the transportation cost with United States Space Transportation System (Space Shuttle) was not reduced.

One of lessons learned through the operation of the US STS is that usage of several kinds of fuels including toxic gas for propulsion and power system caused lower operability. The usage of several kinds of fuels made fueling operation cost increased. In this paper is presented integration system of propulsion and power for the space transportations system as an idea towards this issue. The integration system of energy on propulsion and power is the system in which all propulsion and energy needed in the space transportation system is provided with only single kind of fuel. This system is common in general transportation system such as airplanes and automobiles. Providing all energy with a combination of liquid hydrogen (LH2) and liquid oxygen (LOX) of fuel for main propulsion is considered in this research. Figure 1 shows a conceptual drawing of the LH2/LOX-based integration system on energy on propulsion and power of the space transportation system. Because there is no need to fueling several kinds of fuels, it is expected that the cost for fueling can be reduced. And also, non-use of toxic gas contributes to low operation cost.

In this paper, a conceptual design of the presented integration system of energy on propulsion and power is conducted. The designed systems are evaluated through three parameters that are weight, cost and turn-around time, and effectiveness of the system is discussed.

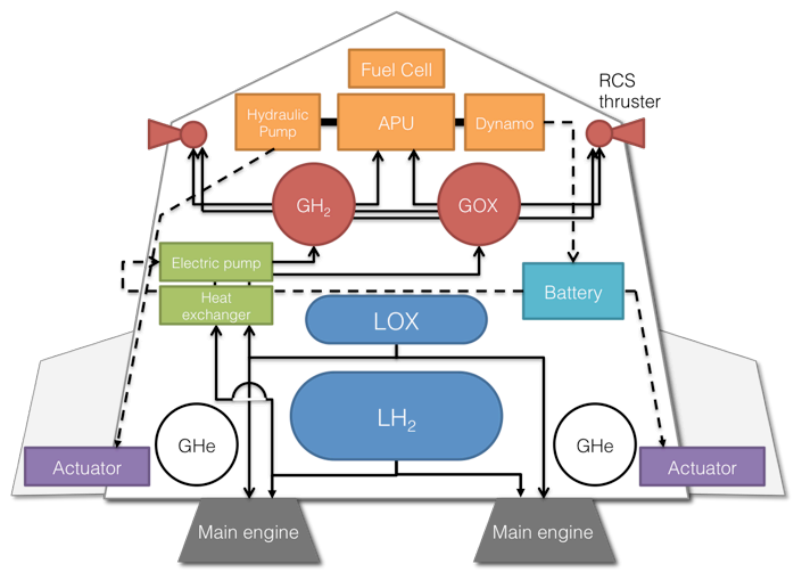

Fig. 1. A conceptual drawing of the LH2/LOX-based integration system on energy on propulsion and power of the space transportation system. 


\section{Conceptual Design Method}

\subsection{Approach}

Figure 2 shows a conceptual drawing of an approach of the conceptual design of the integration system. Assuming a space transportation mission, energy functions and the qualitative performance the transportation vehicle needs are determined. It is the issue considered in this paper how energy sources and energy transfer elements should be connected to comprise the energy system that meets the demanded functions and performance. The considered functions are followings: (1) Main propulsion, (2) Orbit maneuvering propulsion, (3) Attitude control propulsion, (4) Mechanical power production and (5) Electric power production. The evaluation parameters are weight of the system, cost for development, manufacturing and operation of the system, and turn-around time of the vehicle for evaluation of the operability.

\subsection{Modeling}

\subsubsection{Component model}

As for the elements of the energy system, balance of substance and energy is considered as shown in Fig. 2. Energy that has a state parameter, $X_{i n}$, is converted at an energy element to one that has another state parameter, $X_{\text {out }}$, and then is transferred downstream of energy flow. Because the demanded functions and performance at most downstream are given herein, calculations of state parameters of the energy elements are conducted from downstream to upstream on the energy flow. The state parameters, $X_{i n}$, which are needed at the energy conversion elements, are calculated from $X_{\text {out }}$. Here, the state parameters include pressure, mass flow rate, temperature, electricity and so on. The kinds of state parameters depend on the energy conversion elements. Exchanging heat and work with the outside is also considered if needed.

Table 1 shows the modeled elements, the state parameters that are treated in the elements, the models of the state parameters and the weight estimation models of the elements. The models of the state parameters are made using the data of the existing elements. The weight estimation models are made using the data of the existing elements and WATTS ${ }^{2)}$ that are generally used for estimation of space transportation systems.

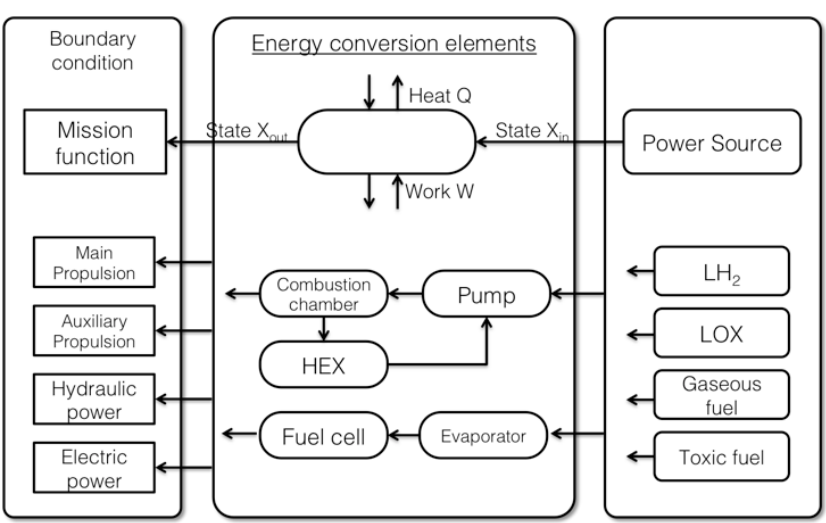

Fig. 2. A conceptual drawing of an approach of the conceptual design of the integration system.

\subsubsection{Cost model}

In this research, TRANSCOST ${ }^{3,4)}$ model, which is a well-known model for estimating cost of space transportation system, is used for the cost estimation model. The model treats vehicle and propulsion system of a wide range of system including manned spacecrafts and advanced airplanes. This model is created thorough statistical processing on development, manufacturing and operation cost of many rockets and spacecrafts developed and planed in the US and Europe and so on.

In the TRANSCOST model, the development cost, $C_{d}$, and the manufacturing cost per a vehicle, $C_{v}$, are expressed respectively as follows;

$$
\begin{gathered}
C_{d}=a M^{x} f_{1} \cdot f_{2} \cdot f_{3} \\
C_{v}=a M^{x} f_{4}
\end{gathered}
$$

Here, $a$ and $x$ are coefficients that depend on the treating vehicle and propulsion system, $M$ is the weight of the stage or the engine of the vehicle. The coefficients, $f_{1}, f_{2}$ and $f_{3}$ affect estimating cost, which depend on the technology level, the quality and the experience of the development team, respectively.

$f_{4}$ is coefficient presenting cost reduction through mass production. The effect of the cost reduction of manufacturing $n$th vehicle is expressed using learning factor, $p$, as follows;

$$
f_{4}=p^{\log n / \log 2}
$$

$p$ is also determined by the vehicle weight and the number of the production of the vehicles. As the number of the manufactured vehicles is fewer, $p$ becomes nearly unity.

From equations (1) and (2), it is shown the development and manufacturing cost largely depend on the weight in this model.

Operation cost, $C_{o}$, is calculated as a summation of ground facility operation cost, propellant cost, flight and mission operation cost and recovery cost. Using annual launch rate, $L$, the operation cost is expressed as following form;

$$
C_{o}=a L^{x}
$$

Total cost, $C_{\text {total }}$, is expressed as a summation of the development, manufacturing and operation cost,

$$
C_{\text {total }}=\sum\left(C_{d}+C_{v}+C_{o}\right)
$$

\subsubsection{Turn-around time model}

Turn-around time is modeled as follows; determining necessary ground operation items and reference work time needed for each of the items, the work times are changed by the integration manner. A series of operation during turn-around are divided to six operation pahses; the ground operation, just-after-landing, moving from the landing pad to a maintenance facility, maintenance, fueling, final preparation. Besides, these phases are divided to more detailed working items ${ }^{5,6)}$. Table 2 shows the working items considered in this paper. 
Y. MARU et al.: Conceptual Study on Hydrogen-Based Integration of Propulsion and Power in Space Transportation Sys.

Regarding reference working time of working item $i$ as $T_{\text {ref, }}^{i}$ trun-around time, $T_{\text {total }}$, is expressed as follows,

$$
T_{\text {total }}=\sum\left(\alpha_{i} T_{\text {ref }}^{i}\right)
$$

Here, $\alpha_{i}$ is a weight coefficient presenting effect of the integration. Table 2 also shows parameters that affect $\alpha_{i}$. The "number of connections" is the number of connections that are needed in the elements of the designed integration energy system. As the integration system has more connections; i.e. the number of connections are large, it can be considered that the necessary time for the operation increases. The "number of hydrazine-usage-components" is the number of components that use hydrazine propellant. It is considered that much working time is needed for handling hydrazine propellant that is toxic gas. Defining number of hydrazine-usage-components in the considered integration case as $n$, and that in the reference case as $n_{r e f}$, the working time of the considered case becomes as $(1 / 2)^{\left(n_{r e f}-n\right)}$ times as the time of the reference case. Considering that the installed fuel is empty at the operation of the moving from the landing pod to the maintenance facility, only dry mass weight affect the needed time of the moving.

\subsubsection{Verification of model}

In order to validate the presented model, the model was applied to a space transportation mission that assumes the US STS. Table 3 shows demanded functions, and fig. 3 shows a block diagram of the energy system. Comparison between the estimated results and the values of the real US STS is presented at Table 4 . The orders of the values agree with each other although there is a little difference. It can be considered that the present model is enough to discuss the characteristics of the integration of the propulsion and power system at conceptual design level.

Table 3. Demanded functions and performances.

\begin{tabular}{lrc} 
Function & \multicolumn{1}{c}{ Performance } & Unit \\
\hline $\begin{array}{l}\text { Main propulsion } \\
\text { Orbit maneuvering }\end{array}$ & $1,670[\mathrm{kN}] \times 3[\mathrm{ea}] \times 520[\mathrm{~s}]$ & $\mathrm{kNs}$ \\
$\begin{array}{l}\text { propulsion } \\
\text { Attitude control } \\
\text { propulsion }\end{array}$ & $27[\mathrm{kN}] \times 2[\mathrm{ea}] \times 600[\mathrm{~s}]$ & $\mathrm{kNs}$ \\
$\begin{array}{l}\text { Mechanical power } \\
\text { Electrical power }\end{array}$ & $101[\mathrm{~kW}] \times 3[\mathrm{kN}] \times 38[\mathrm{ea}] \times 300[\mathrm{~s}]$ & $\mathrm{kNs}$ \\
& $7[\mathrm{~kW}] \times 3[\mathrm{ea}] \times 7[\mathrm{day}] \times 24[\mathrm{~h} /$ day $] \times 60[\mathrm{~s} / \mathrm{min}]$ & $\mathrm{kJ}$ \\
\end{tabular}

Table 4. Comparison between estimation results and actual values in US STS.

\begin{tabular}{|c|c|c|c|}
\hline Parameter & Component & Estimation & US STS \\
\hline \multirow{7}{*}{$\begin{array}{l}\text { Weight } \\
{[\mathrm{kg}]}\end{array}$} & SSME & 4542.1 & 7484.8 \\
\hline & $\begin{array}{l}\text { Fuel for main } \\
\text { propulsion }\end{array}$ & 78156.0 & 102976.7 \\
\hline & $\begin{array}{l}\text { Oxidizer for main } \\
\text { propulsion }\end{array}$ & 494988.0 & 610778.8 \\
\hline & $\begin{array}{l}\text { Tank for main } \\
\text { propulsion }\end{array}$ & 18148.3 & 20297.0 \\
\hline & Propellant for OME & 10843.0 & 9602.7 \\
\hline & Propellant for RCS & 3277.6 & 3333.1 \\
\hline & Total & 635000 & 755000 \\
\hline \multirow[t]{2}{*}{ Cost $[\mathrm{B} \$]$} & Total & 121.87 & 200 \\
\hline & $\begin{array}{l}\text { Operation cost for one } \\
\text { flight }\end{array}$ & 0.59 & 0.4 \\
\hline
\end{tabular}

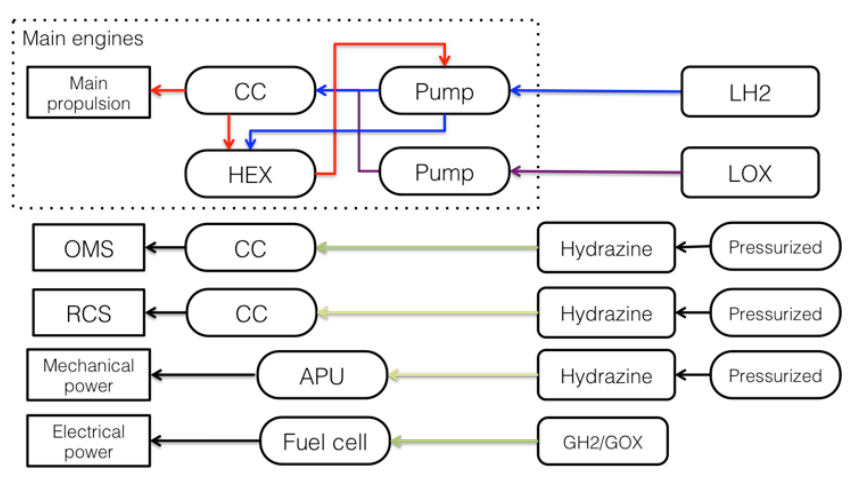

Fig. 3. The block diagram of the energy system assumed in the model validation.

\section{Evaluation of Integrated System of Propulsion and Power}

\subsection{Assumed space mission}

In this paper, "construction of space solar power system (satellite), SSPS on GEO " is considered as the assumed space mission. According to 7), the practical SSPS weighs 30,000 ton. It is considered in this research that necessary 30,000 ton-material is transported in five years to the low earth orbit by transportation vehicles whose maximum payload weight is 20 ton. The demanded functions and performance are same as shown in table 3. The reference energy system is same as shown in fig. 3 .

\subsection{Considered cases of integration of propulsion and power}

Table 5 shows propulsion and power system cases examined in this paper. These cases are selected considering reduction of kinds of propellants, non-usage of toxic gas and decrease of number of operation work items.

\subsection{Results and discussion}

\subsubsection{Compensation of increase in energy system weight}

If the weight of energy system increases, it is necessary to increase the fuel because the increase must be compensated. Besides, the weight of the structure also increases for the increase in the fuel, and then the increase in the structure increases the weight of the fuel. A weight-increase-spiral is generated. In this paper, this influence is considered as follows. Defining the weight of the fuel for the main propulsion in the reference system as $m_{p 0}$, the structure weight as $m_{s 0}$, variations in the fuel and the structure at changing the energy system as $\Delta m_{p}$ and $\Delta m_{s}$, respectively, and the additional fuel weight that is needed as $m_{p a}$, eq. (7) can be expressed using specific impulse, Isp, because necessary change in velocity (delta-v) is constant,

$$
g I s p \log \frac{m_{p 0}+m_{s 0}}{m_{s 0}}=g I s p \log \frac{\left(m_{p 0}+\Delta m_{p}\right)+\left(m_{s 0}+\Delta m_{s}\right)+m_{p a}}{\left(m_{s 0}+\Delta m_{s}\right)}
$$

Here, Isp is specific impulse. $m_{p a}$ is calculated for each case using eq.(7) and is reflected to the evaluation of the weight. Actually, the additional structure weight, $m_{s a}$, according to the additional fuel weight $m_{p a}$ should be also considered. However, because $m_{s a}$ can be modeled to be proportional to $m_{p a}$, the only 


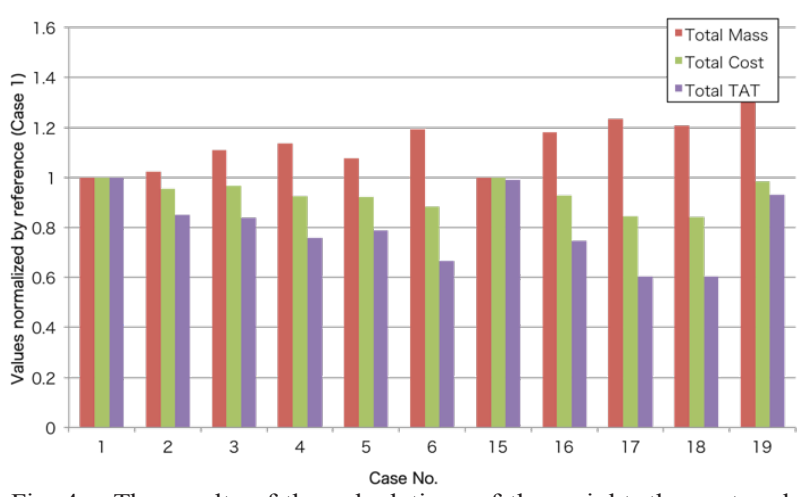

Fig. 4. The results of the calculations of the weight, the cost and the turn-around time.

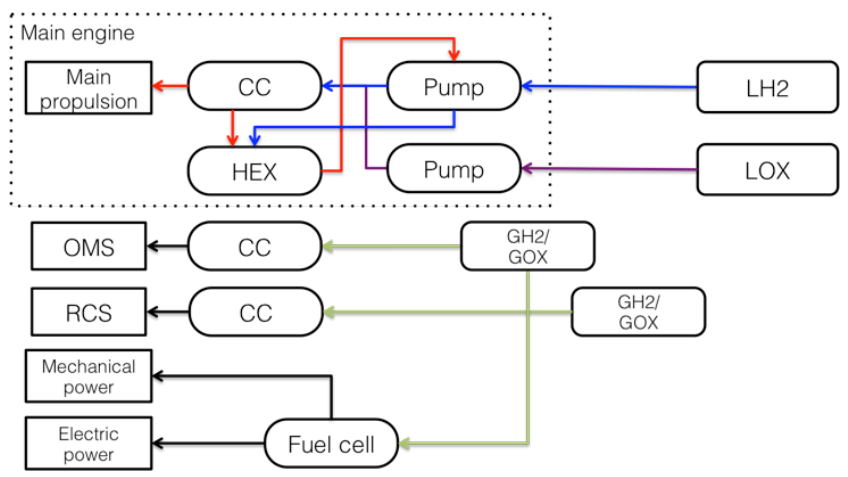

Fig. 5. System diagram of Case 18 that makes the total cost most inexpensive.

consideration of $m_{p a}$ is enough to evaluate the trend of the influence of the weight-increase-spiral. Consequently, it is proved that the weight of case 7-15 and 20-23 increases extremely. Therefore, in the following discussion, these cases will be excluded.

\subsubsection{Findings related to cost}

Figure 4 shows the results of the calculations of the weight, the cost and the turn-around time. The values in fig. 4 are normalized by the values of the reference case. Case 18 makes the total cost minimum. Figure 5 shows the energy system diagram of case 18, where mechanical and electrical power are integrated through fuel cells, the fuels of the OME and the RCS are changed to $\mathrm{GH}_{2} / \mathrm{GOX}$, and the accumulators for the fuel cells and the OME are integrated. Table 6 summarizes the system of case 18 . Though the weight is larger by $20 \%$ than the smallest case, it has lower total cost by $15 \%$ (equivalent to about 44 billion dollars) compared to most costly case and shorter turn-around time by $40 \%$ compared to the longest case.

Table 6. System summary of case \#18

\begin{tabular}{lc}
\hline Weight [ton] & 766 \\
Total cost [B\$] & 239 \\
Development cost [B\$] & 39 \\
Manufacturing cost [B $\$$ ] & 46 \\
Operation cost [B $\$$ ] & 153 \\
Turn around time [day] & 6.7 \\
Number of vehicles that need to be manufactured & 7 \\
Number of launches of a vehicle & 46 \\
\hline
\end{tabular}

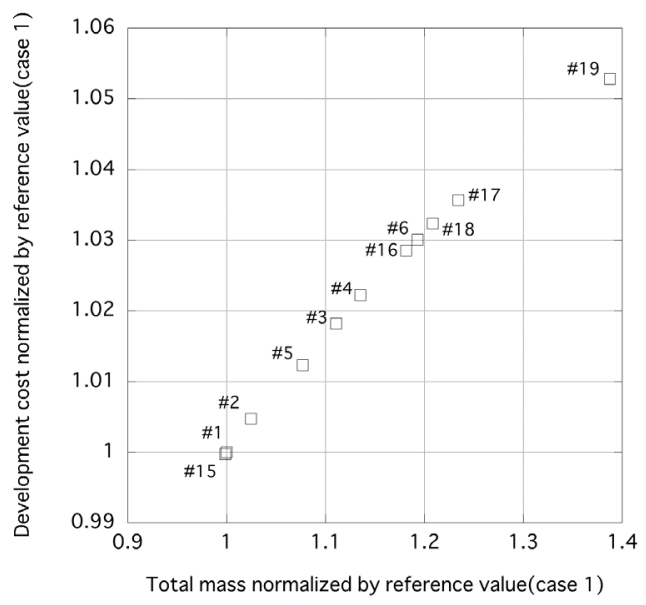

Fig. 6. Relation between the weight and the development cost in the calculation result.

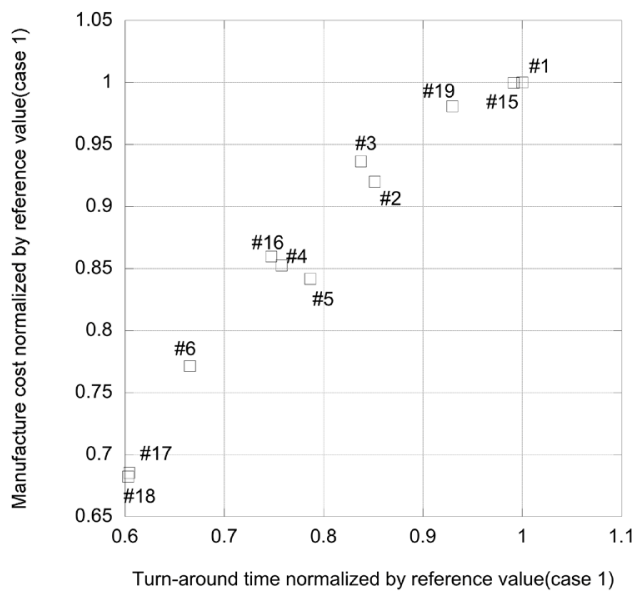

Fig. 7. Relation between the turn-around time and the manufacture cost in the calculation result.

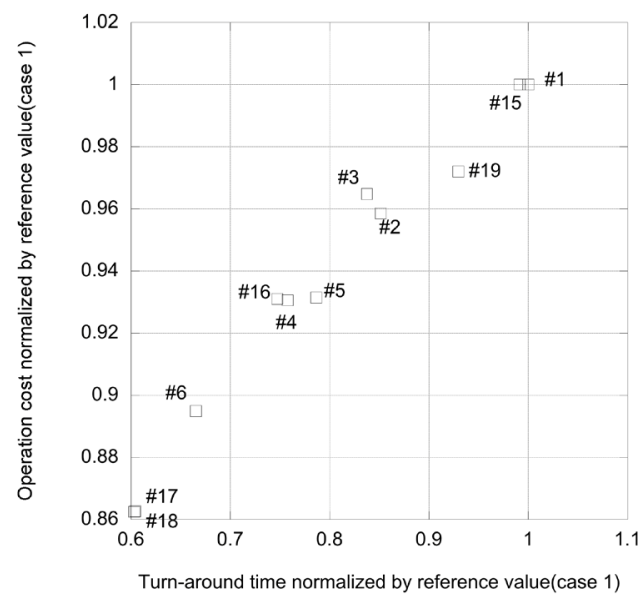

Fig. 8. Relation between the turn-around time and the operation cost in the calculation result.

The development cost in the present model depends on the weight of the system. The manufacturing cost depends on the quantity of manufacture, or launch rate, which depends on turn-around time. Therefore, the turn-around time has to be improved in order to suppress the manufacturing cost. And also, the operation cost depends on the launch rate, or the turn-around 


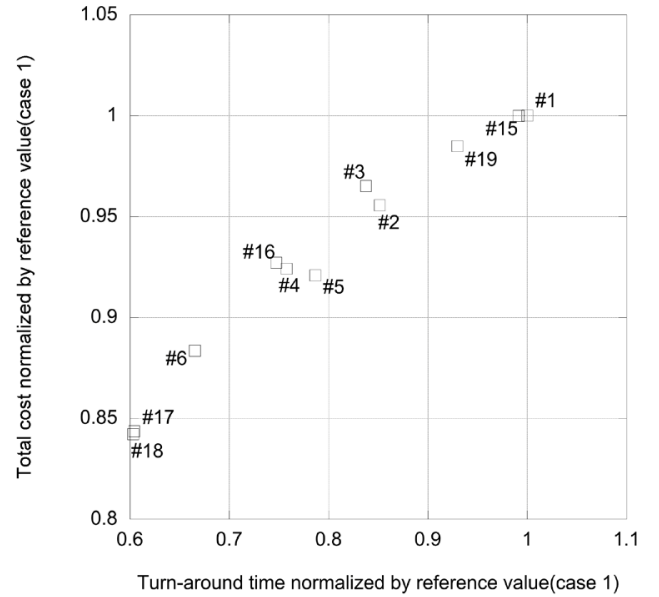

Fig. 9. Relation between the turn-around time and the total cost or life-cycle-cost in the calculation result.

time. These relationships are shown in figs.6-8. The case that has the most expensive total cost has the longest turn-around time, and the case that has the most inexpensive total cost has the shortest turn-around time. Comparing the order of the total cost with that of the turn-around time, both of the orders are generally consistent with each other as shown in fig.9. This suggests that it is necessary for the space transportation system operated at low cost to reduce the turn-around time largely.

\subsubsection{Findings related to turn around time}

The usage of the toxic propellant has most influence on the turn-around time. Figure 10 shows relation between the amount of hydrazine fuel and the turn-around time, in which it is seen that the turn-around time is reduced by about $40 \%$ without the use of hydrazine fuel. And also, the integration suppressing the number of the elements has better effect on the turn-around time. In order to suppress the number of the elements, (1) the fuel tanks of same kinds and phase of fuel should be integrated, (2) the batteries should be used in case that the demanded performance is small relatively. In that case, the number of the elements can be reduced without additional elements such as accumulators. However, use of the batteries affects positively only in the case whose required energy is small. It is noted that the weight of the batteries becomes extremely large, which results in failure of the system.

\subsubsection{Findings related to weight}

In order to suppress the weight, firstly, hydrogen and oxygen fuel should be used instead of hydrazine because the fuel weight can be largely reduced.

It is possible that the structure weight is increased in the case that additional accumulators or batteries are needed. The accumulators are necessary in the case that hydrogen and oxygen fuel are used, and heat exchanger and batteries are necessary in the case that gaseous fuel has to be generated from cryogenic liquid fuel. The additions of these elements tend to make the weight increased. Figure 11 compares the dry weight of the system of each case. The cause of the increase in the weight is the additions of such elements as accumulators. This means that the integration of the components that uses

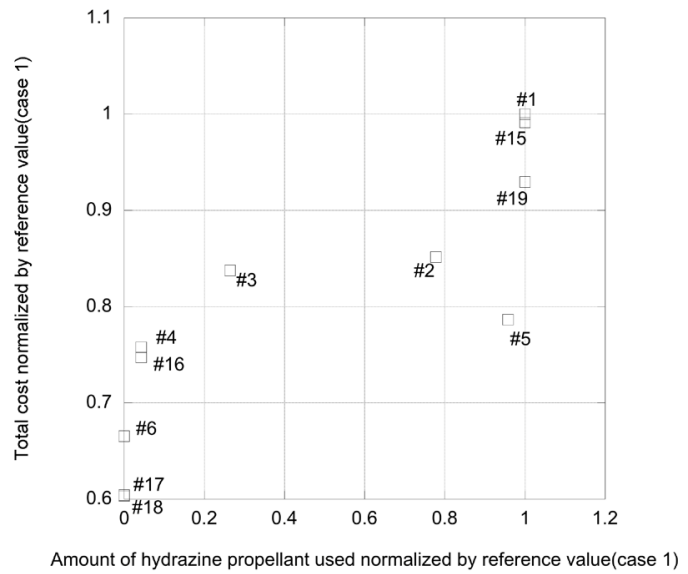

Fig. 10. Relation between the amount of hydrazine propellant used in the energy system and the turn-around time in the calculation result.

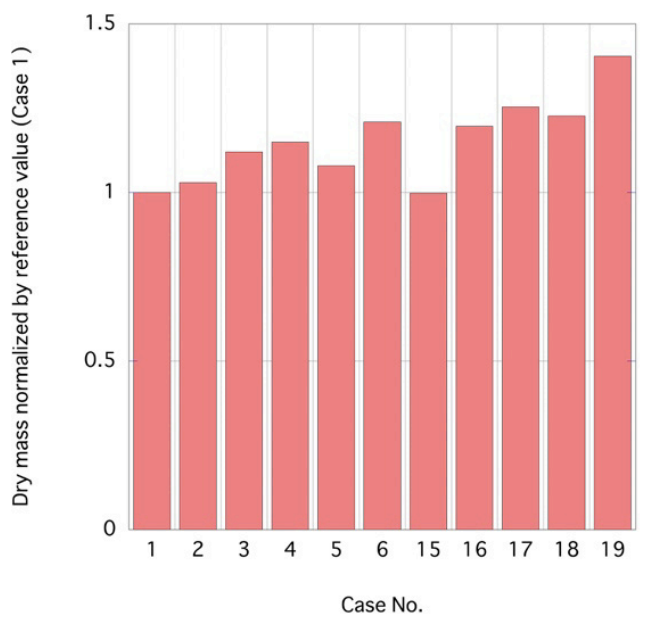

Fig. 11. The calculated dry mass of each case.

hydrogen and oxygen fuel increase the dry mass in contrast to the fuel mass.

The fuels of same kind and phase should be integrated into a large tank. As mentioned above, the integration of the fuels that have same kind and phase is favorable in the viewpoint of suppressing the turn-around time. If the system has several fuel tanks, integration of the fuels into a larger tank makes more suppression of the weight increase expected.

\subsubsection{Further suggestion for more efficient system}

Increase of the number of the connections needs more turn-around time because of checkouts for leaks at the connections, and causes deteriorations in the operation cost. Efficient manners of the checkouts, such as health monitoring system, are desired. If the working time for the piping connections is reduced by a factor of ten, the turn-around time can be improved by $39 \%$.

In the present space transportation system, relatively much time is used for the fueling. If the fueling rate is made more quickly by 10 times, the turn-around time can be improved by $14 \%$.

It is recommended that the maintenance operation without moving be considered. In the maintenance operation of the US STS, the vehicle must be moved to the maintenance facility 
that is away from the landing pod. However, the moving operation increases not only the turn-around time but also risks of accidents and troubles. If the moving operation is eliminated, the turn-around time can be reduced by $6 \%$.

\section{Conclusion}

In this paper, the integration system of the propulsion and power for efficient operation of the space transportation systems like automobiles and aircrafts was introduced, and the energy system model that can deal with the integration and replacement of fuels and elements was developed. Applying the presented model to the space transportation system for building the SSPS, the effectiveness of the integration was evaluated in the viewpoint of weight, cost and turn-around time. The integration case that had the most inexpensive total cost, or the life-cycle cost, has also brought the smallest turn-around time though the additional weight was caused. In order to realize massive and frequent space transportation with low cost, it is indispensable to reduce the turn-around time. The use of toxic propellants affects the turn-around time. Reductions of the number of the elements and the connections, for example the integration of fuel tanks that have same kind and phase, are also effective on shortening the turn-around time. As for the weight, the use of hydrogen and oxygen makes the weight decreased. It was proved that the addition of batteries and accumulators caused increase in the weight. Several suggestions for the system design and the operation, which include the reduction of the duration for checking-out of the piping connections, shortening the duration for the fueling and the maintenance without moving the vehicle, are conducted.

Future works are as follows.

- Making the model more precise and detailed.

- Making the demanded functions multi-dimensional, such as considering several flight and operation phases.

- Considering several evaluation parameters.

\section{References}

1) Bimley, R. L., et al.: PRELIMINARY DESIGN OF AN AUXILIARY POWER UNIT FOR THE SPACE SHUTTLE-COMPONENT AND SYSTEM CONFIGURATION SCREENING ANALYSIS, NASA-CR-1928, 1971

2) Glatt, C.R.: WAATS - A Computer Program for Weights Analysis of Advanced Transportation Systems, NASA CR-2420, 1974.

3) Koelle, D. E.: The transcost-model for launch vehicle cost estimation and its application to future systems analysis, Acta Astronautica, 11 (1984), pp.803-817.

4) Koelle, D. E.: Handbook of Cost Engineering for Space Transportation Systems with Transcost 7.0, TCS-TransCostSystems, Ottobrunn, 2000

5) NASA and BOEING: Shuttle Ground Operations Efficiencies / Technologies Study, TECHNICAL INFORMATION SHEETS, FINAL REPORT Volume 5, Phase 1, NAS10-11344, 1987.

6) Wilson, J. R., et al.: Analysis of Space Shuttle ground operations, Simulation, 38 (1982), pp.187-203.

7) Suzuki, K.: Study on 10,000kW-class Space Solar Power System, Master's Thesis, University of Tokyo, 1991 (in Japanese). 
Y. MARU et al.: Conceptual Study on Hydrogen-Based Integration of Propulsion and Power in Space Transportation Sys.

Table 1. Component models.

\begin{tabular}{|c|c|c|c|c|}
\hline Component & State parameters & State parameter model & Weight model & Note \\
\hline $\begin{array}{l}\text { Combustion } \\
\text { chamber }\end{array}$ & $\begin{array}{l}\text { Pressure, } P_{c c}[\mathrm{MPa}] \\
\text { Mass flow rate, } \dot{m}_{c c}[\mathrm{~kg} / \mathrm{s}] \\
\text { Engine thrust, } T h[\mathrm{kN}]\end{array}$ & $\begin{array}{l}P_{c c}=0.01 T h \\
\dot{m}_{c c, \text { fuel }}=3 P_{c c} \\
\dot{m}_{c c, o x}=19 P_{c c}\end{array}$ & $M_{c c}=56.449 \ln (T h)+26.59$ & \\
\hline Turbo pump & $\begin{array}{l}\text { Pressure, } P_{\text {pump }}[\mathrm{MPa}] \\
\text { Mass flow rate, } \dot{m}_{\text {pump }}[\mathrm{kg} / \mathrm{s}] \\
\text { Work, } W_{\text {pump }}\end{array}$ & $\begin{array}{l}P_{\text {pump }, \text { fuel }}=2 P_{X^{\prime}} \\
P_{\text {pump }, \text { ox }}=1.5 P_{X^{\prime}} \\
\dot{m}_{\text {pump }}=\dot{m}_{X^{\prime}} \\
W_{\text {pump }}=\dot{m}_{\text {pump }} \times P_{\text {pump }} / \eta\end{array}$ & $\begin{array}{l}M_{\text {pump }} \\
=101.02\left(P_{\text {pump }} \cdot \dot{m}_{\text {pump }}^{1.5}\right)^{0.4059}\end{array}$ & $\begin{array}{l}\text { Mass flow rate is conserved. } \\
\eta \text { :mechanical efficiency of } \\
\text { pump. }\end{array}$ \\
\hline $\begin{array}{l}\text { Heat } \\
\text { exchanger } \\
\text { (including } \\
\text { vaporizer) }\end{array}$ & $\begin{array}{l}\text { Pressure, } P_{h e x}[\mathrm{MPa}] \\
\text { Mass flow rate, } \dot{m}_{\text {hex }}[\mathrm{kg} / \mathrm{s}] \\
\text { Required exchanging heat, } Q_{r e q} \\
{[\mathrm{~kW}]} \\
\text { Heat transfer area, } A_{\text {hex }}\left[\mathrm{m}^{2}\right]\end{array}$ & $\begin{array}{l}P_{\text {hex }}=P_{X^{\prime}} \\
\dot{m}_{\text {hex }}=\dot{m}_{X^{\prime}} \\
A_{\text {hex }}=Q_{\text {req }} / h_{c}\left(T_{w c}-T_{X^{\prime}}\right)\end{array}$ & $M_{\text {hex }}=29.4 A_{\text {hex }}+20.45$ & $\begin{array}{l}h_{c} \text { :heat transfer coefficient } \\
T_{w c} \text { :temperature of heat } \\
\text { transfer surface }\end{array}$ \\
\hline $\begin{array}{l}\text { Auxiliary } \\
\text { power unit } \\
\text { (APU) }\end{array}$ & $\begin{array}{l}\text { Mass flow rate, } \dot{m}_{a p u}[\mathrm{~kg} / \mathrm{s}] \\
\text { Required work, } W_{a p u}[\mathrm{~kW}] \\
\text { Radiating heat, } Q_{a p u}[\mathrm{~kW}]\end{array}$ & $\begin{aligned} \dot{m}_{a p u} & =f\left(W_{a p u}\right) \\
Q_{a p u} & =\dot{m}_{a p u} \cdot L H V-W_{a p u}\end{aligned}$ & $M_{a p u}=0.44 W_{a p u}+0.2$ & $\begin{array}{l}\dot{m}_{a p u} \text { is taken from } \\
\text { reference. }^{1)} \\
\text { LHV :lower heating value }\end{array}$ \\
\hline Fuel cell (FC) & $\begin{array}{l}\text { Volume flow rate, } q[\mathrm{sccm}] \\
\text { Required output power, } W_{f c} \\
{[\mathrm{~W}]} \\
\text { Radiating heat, } Q_{f c}[\mathrm{~W}]\end{array}$ & $\begin{aligned} q_{H 2} & =11.8 W_{f c} \\
q_{O 2} & =14.8 W_{f c} \\
Q_{f c} & =(1-\eta) / \eta \cdot P\end{aligned}$ & $M_{f c}=0.013 W_{f c}+0.0017$ & $\begin{array}{l}\eta \text { :power generation } \\
\text { efficiency of fuel cell, } 0.4 \text {. }\end{array}$ \\
\hline Battery & $\begin{array}{l}\text { Required output power, } W_{b a t} \\
{[\mathrm{~W}]}\end{array}$ & & $M_{b a t}=W_{b a t} t_{b a t} / 52.5$ & $\begin{array}{l}t_{\text {bat }}: \text { required working } \\
\text { duration [hour] }\end{array}$ \\
\hline $\begin{array}{l}\text { Pressurized } \\
\text { gas storage }\end{array}$ & Pressurizing volume, $V\left[\mathrm{~m}^{3}\right]$ & & $M_{\text {pres }}=0.028 V_{\text {fuel }}+0.153 V_{o x}$ & \\
\hline $\begin{array}{l}\text { Propellant } \\
\text { tank }\end{array}$ & Propellant mass, $M[\mathrm{~kg}]$ & & $\begin{array}{l}M_{L H 2 \text { tank }}=0.033 M_{L H 2} / \rho_{L H 2} \\
M_{\text {LoXtank }}=0.080 M_{L O X} / \rho_{L O X} \\
M_{H y d r a z i n e t a n k} \\
=0.024 M_{\text {Hydrazine }}\end{array}$ & $\rho:$ density of propellant \\
\hline $\begin{array}{l}\text { Insulator for } \\
\text { cryogenic } \\
\text { tank }\end{array}$ & Tank volume, $V\left[\mathrm{~m}^{3}\right]$ & & $\begin{aligned} M_{\text {insLH2tank }} & =0.6 S_{\text {LH2tank }} \\
M_{\text {insLOXtank }} & =0.25 S_{\text {LOXtank }}\end{aligned}$ & $\begin{array}{l}S_{L H 2 \operatorname{tank}}=4 \pi r_{\text {tank }}^{2} \\
r_{\text {tank }}=(3 / 4 \pi) V_{\text {tank }}^{1 / 3}\end{array}$ \\
\hline
\end{tabular}


Trans. JSASS Aerospace Tech. Japan Vol. 14, No. ists30 (2016)

Table 2. Turn-around time model.

\begin{tabular}{|c|c|c|c|}
\hline Major operation items & Minor operation items & $T_{\text {base }}$ & Factors that affect to $\alpha_{i}$ \\
\hline \multirow[t]{3}{*}{ Operation after landing } & Check of propellant leak & 1 & $\begin{array}{l}\text { Number of connections, number of } \\
\text { hydrazine-usage-components }\end{array}$ \\
\hline & Reducing tank pressure & 1 & Number of tanks \\
\hline & Unloading of payload & 1 & \\
\hline $\begin{array}{l}\text { Moving from landing pad to } \\
\text { maintenance facility }\end{array}$ & Moving & 1 & Dry mass \\
\hline \multirow[t]{8}{*}{ Check-out and maintenance } & Connection of ground support equipment & 2 & \\
\hline & Propulsion system maintenance & 10 & Number of connections related to propulsion \\
\hline & Tank system maintenance & 5 & Number of connections related to tank \\
\hline & Hydraulic system maintenance & 5 & Number of connections related to hydraulic system \\
\hline & Electric system maintenance & 5 & Number of connections related to electlic system \\
\hline & Appearance check-out & 10 & number of hydrazine-usage-components \\
\hline & Installing components & 10 & Number of components \\
\hline & Equipping boosters & 5 & \\
\hline \multirow{3}{*}{$\begin{array}{l}\text { Moving from maintenance } \\
\text { facility to launch pad }\end{array}$} & Preparation for moving & 0.5 & \\
\hline & Moving & 4 & Dry mass \\
\hline & Setting to launch pad & 4 & \\
\hline \multirow[t]{3}{*}{ Fueling } & Filling gaseous fuel & 4 & Total mass of gaseous fuel \\
\hline & Filling hypergolic gas fuel & 4 & Total mass of hypergolic fuel \\
\hline & Filling liquid fuel & 4 & Total mass of liquid fuel \\
\hline \multirow[t]{3}{*}{ Final preparation } & Installing payload & 6 & \\
\hline & Check-out I/F & 8 & \\
\hline & Separating ground support equipment & 2 & Number of connections related to tanks \\
\hline
\end{tabular}

Table 5. Considered integrated system cases.

\begin{tabular}{|c|c|}
\hline Case number & Summarized comment \\
\hline 1 & Reference case. (Propulsion and power system of space shuttle is assumed) \\
\hline 2 & Integration of tanks for main propulsion and RCS. \\
\hline 3 & Integration of tanks for main propulsion and OMS. \\
\hline 4 & Integration of tanks for main propulsion, RCS and OMS. \\
\hline 5 & Mechanical and electrical power is generated from only fuel cells. \\
\hline 6 & Integration of tanks for main propulsion and fuel cells adding to case 4 and 5 . \\
\hline 7 & Integration of tanks for RCS and fuel cells adding to case 2 . \\
\hline 8 & Integration of tanks for OMS and fuel cells adding to case 3 . \\
\hline 9 & Integration of tanks for RCS and fuel cells adding to case 2 and 5. \\
\hline 10 & Integration of tanks for OMS and fuel cells adding to case 3 and 5. \\
\hline 11 & Integration of tanks for RCS and fuel cells adding to case 4 and 5. \\
\hline 12 & Integration of tanks for OMS and fuel cells adding to case 4 and 5. \\
\hline 13 & Mechanical and electrical power is generated from APU fueled with hydrazine. \\
\hline 14 & Mechanical and electrical power is generated from APU fueled with $\mathrm{GH}_{2} / \mathrm{GOX}$. \\
\hline 15 & Integration of tanks for RCS and OMS, which are fueled with hydrazine. \\
\hline 16 & Integration of tanks for RCS and OMS, which are fueled with $\mathrm{GH}_{2} / \mathrm{GOX}$. \\
\hline 17 & RCS and OMS are fueled with $\mathrm{GH}_{2} / \mathrm{GOX}$, and integration of tanks for fuel cells and RCS, adding to case 5 . \\
\hline 18 & RCS and OMS are fueled with $\mathrm{GH}_{2} / \mathrm{GOX}$, and integration of tanks for fuel cells and OMS, adding to case 5 . \\
\hline 19 & Electrical power is generated from batteries. \\
\hline 20 & RCS and OMS are fueled with $\mathrm{GH}_{2} / \mathrm{GOX}$ adding to case 19 . \\
\hline 21 & Mechanical power is generated from batteries adding to case 20 . \\
\hline 22 & Case 16 and 21 are conducted at same time. \\
\hline 23 & Case 16 and 20 are conducted at same time. \\
\hline
\end{tabular}

